\title{
An estimate of bedload discharge in rivers with passive acoustic measurements: Towards a generalized calibration curve?
}

\author{
Thomas Geay ${ }^{1}$, Sébastien Zanker ${ }^{2}$, Alexandre Hauet ${ }^{2}$, Clement Misset $^{3}$, and Alain Recking ${ }^{3}$ \\ ${ }^{1}$ Univ. Grenoble Alpes, CNRS, Grenoble INP, GIPSA-lab, 38000 Grenoble, France. \\ ${ }^{2}$ EDF, Division Technique Générale, 38000, Grenoble, France. \\ ${ }^{3}$ IRSTEA, UR ETGR, Univ. Grenoble Alpes, 38000 Grenoble, France.
}

\begin{abstract}
Bedload Self-Generated Noise (SGN) measurements consist in deploying an underwater microphone (i.e. a hydrophone) in the river and to record the ambient noise. The use of hydrophones to measure bedload characteristics (flux, spatial distribution, granulometry) could be of interest as it can be more easily and rapidly deployed than physical samplers in rivers. Several measurement campaigns where conducted during spring and summer 2017 in 5 alpine rivers with contrasted transport conditions (bedload $D_{50}$ between 1 and $40 \mathrm{~mm}$ ) and varying slopes (0.05 to $1 \%$ ). Physical sampling measurements were done from a bridge along the river cross section for specific bedload flux varying between 10 and $150 \mathrm{~g} . \mathrm{m}^{-1} \mathrm{~s}^{-1}$. Bedload SGN measurements were obtained with a small board equipped with a hydrophone and deriving downstream the bridge within a 10 to 50 $\mathrm{m}$ long river section. For 2 of the 5 rivers, acoustic Doppler current profilers (ADCP) were also deployed along the river cross-section to provide a surrogate measurement of apparent bedload velocity. As a result, we have been able to draw an acoustic 1D-map of the river bottom, derived from the SGN sub-surface measurements obtained with the deriving board. The results show a coherent relation between the riverbed acoustic maps and the physical samplings for 3 rivers over 5 . Bedload profile were less consistent with SGN measurements when bedload transport was localized in a narrow channel. The apparent bedload velocities obtained with ADCP for 2 rivers are consitent with the physical samplings (bedload location and flux distribution) but a slight bias was observed and is attributed to grainsize sorting effects along the cross-section. Finally, when plotting together 4 over 5 rivers, an almost linear relation can be established between bedload discharge (computed with physical samplings data) and the average acoustic response (i.e acoustic power averaged over the crosssection). This result suggests that a generalized calibration curve could exist between bedload SGN and bedload discharge. The existence of an outsider is interpreted as a problem related to propagation effects. Further researches should therefore concentrate their effort on deconvoluting SGN signals from propagation effects to give a better confident proxy for bedload discharge measurement in different rivers types.
\end{abstract}




\section{Introduction}

Several bedload-surrogate technologies are in development to supply or complement bedload data with standard direct sampling methods [1]. In this study, both passive and active acoustic technologies were used. Acoustic measurements are compared to pressuredifference sampler measurements.

Passive acoustic consists in recording the ambient noise with hydrophones. When bedload particles move, an acoustic noise is generated by bedload impacts on the riverbed. This bedload Self-Generated Noise (SGN) is measured with hydrophones that are deployed in the watercourse. Hydrophones can be used to continuously monitor bedload transport $[2,3$, $4]$ or to explore the spatial variations of bedload processes $[5,6]$. Theoretical and laboratory studies [7, 8] showed that the power (in $\mu \mathrm{Pa}^{2}$ ) of bedload SGN is dependent on two principal factors: (1) bedload flux and (2) the impact velocities. The acoustic power of SGN has been related to bedload fluxes in several field studies $[3,4]$. The complexity of SGN measurements is especially related to the effect of propagation conditioning the acoustic signals $[9,10]$. The hydrophone signals are composed of sounds originating from single impacts at different distances from the sensor. The listening distance of a hydrophone is not known but is in part related to the attenuation laws of acoustic signals. As these propagation laws depend on the river characteristics such as the bed roughness [11] or the water depth $[9,10]$, it can be concluded that the listening distance of a hydrophone is river dependent. Despite these uncertainties, for the first time, a study has been designed to explore the sitespecificity of the relationship between bedload SGN measurements and bedload flux. This has been done in a set of gravel-bed rivers having different characteristics (varying slopes and bedload granulometries). Preliminary results are presented in this paper.

Active acoustic measurement consists in deploying an acoustic Doppler current profiler (aDcp) in a fixed position or with a difference Global Positioning System (GPS). It measures an apparent bedload velocity originated from a bias between the velocity of the aDcp monitored with the bottom tracking and the real velocity of the device (for example, monitored with a D-GPS). This measure of an apparent bedload velocity has been found to correlate with bedload fluxes in several studies [12, 13, 14]. As an easy way to monitor bedload transport, this method has been used in two of our field sites. The capacity of the aDcp to provide bedload cross-sectional variations has been tested.

\section{Method}

\subsection{Field sites}

Bedload monitoring was performed in five alpine gravel-bed rivers (Table 1) by using bedload pressure-difference samplers, passive and active measurements (Fig. 1). Studied river bed slopes vary from 0.05 to $1 \%$ (Table 1 ).

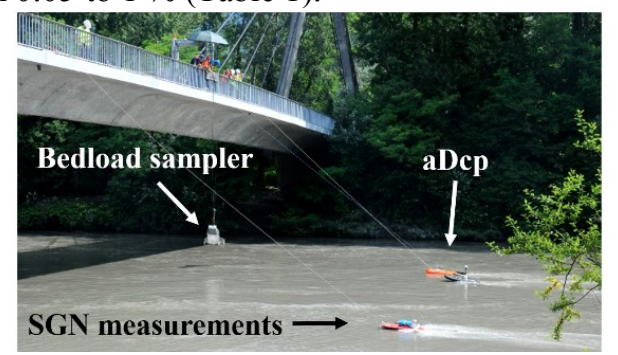

Fig. 1. Bedload sampling, aDcp and SGN measurements deployed in the Isère River (Grenoble, France). 
Table 1. Bedload sampling characteristics

\begin{tabular}{|c|c|c|c|c|c|c|c|}
\hline River & $\begin{array}{l}\text { Slope } \\
(\%)\end{array}$ & $\begin{array}{l}\text { River } \\
\text { Width } \\
\text { (m) }\end{array}$ & $\begin{array}{l}\text { Date in } \\
2017\end{array}$ & $\begin{array}{l}\text { Sample } \\
\text { number }\end{array}$ & $\begin{array}{l}\text { Discharge } \\
\left(\mathrm{m}^{3} / \mathrm{s}\right)\end{array}$ & $\begin{array}{l}\text { Froude } \\
\text { number } \\
(-)\end{array}$ & $\begin{array}{l}\text { Bedload } \\
{\left[D_{50} ; D_{84}\right]} \\
(\mathrm{mm})\end{array}$ \\
\hline Arve & 0.75 & 14 & $\begin{array}{l}06-27 \\
06-28\end{array}$ & $\begin{array}{l}11 \\
15\end{array}$ & $\begin{array}{l}38 \\
29\end{array}$ & $\begin{array}{l}0.62 \\
0.57\end{array}$ & $\begin{array}{l}{[1 ; 4]} \\
{[1 ; 3]}\end{array}$ \\
\hline $\begin{array}{l}\text { Grand } \\
\text { Buëch }\end{array}$ & 0.70 & 13 & $05-15$ & 23 & 13 & 0.69 & {$[39 ; 63]$} \\
\hline Isère & 0.05 & 60 & 06-06 & 47 & 237 & 0.27 & {$[2 ; 13]$} \\
\hline Romanche & 0.13 & 33 & $06-14$ & 38 & 55 & 0.40 & {$[1 ; 3]$} \\
\hline Séveraisse & 1.00 & 13 & $\begin{array}{l}05-17 \\
05-30\end{array}$ & $\begin{array}{l}54 \\
28\end{array}$ & $\begin{array}{l}14 \\
16\end{array}$ & $\begin{array}{l}0.74 \\
0.72\end{array}$ & $\begin{array}{l}{[5 ; 48]} \\
{[12 ; 52]}\end{array}$ \\
\hline
\end{tabular}

\subsection{Bedload Sampling}

Bedload transport was sampled from bridges. A cable-suspended Toutle River 2 (entrance of 305 by $152 \mathrm{~mm}, 0.75 \mathrm{~mm}$ mesh bag) was used in the Isère and Romanche Rivers. A handheld Elwha sampler (entrance of 229 by $152 \mathrm{~mm}, 0.5 \mathrm{~mm}$ mesh bag) was operated in all the field sites (except the Isère River). Six to twelve cross-sectional locations were monitored. Each location was repeated as much as possible during the measurement period. The duration of each sample varied between 30 seconds to 8 minutes to ensure smaller sampled volumes than sampler capacities. Each sample was sieved and weighted. A specific flux $q_{s}$ (for each location X) was obtained by averaging the sampled mass over the total sampling duration:

$$
q_{s}(X)=\frac{\sum_{i} M_{i}(X \pm \Delta X)}{W_{\text {sampler }} \sum_{i} d_{i}(X \pm \Delta X)}
$$

where $M_{i}(\mathrm{~g})$ and $d_{i}(\mathrm{~s})$ are the mass and duration of sample $i . i$ are the samples located in $\mathrm{X}$ $\pm \Delta X$, where $\Delta X(\mathrm{~m})$ is a window of $1 \mathrm{~m}$ used to average the data in the spatial domain. For each location, a standard deviation is also computed. Missing value of the profile are linearly interpolated. Finally, the average-specific bedload flux is obtained by integrating the profile:

$$
\overline{q_{s}}=\frac{\int q_{s}(X) d X}{W_{\text {river }}}
$$

Where $W_{\text {river }}(\mathrm{m})$ is the river width. An estimated standard deviation of the averaged specific flux is computed by summing the squared standard deviation obtained at each location:

$$
\overline{\sigma_{q s}}=\frac{\sqrt{\int \sigma_{q s}(X)^{2} d X}}{W_{\text {river }}}
$$




\subsection{Passive acoustic monitoring}

Bedload Self-Generated Noise (SGN) was monitored with HTI-96 or HTI-99 hydrophones plugged into an EA-SDA14 card (RTSys company). Raw acoustic signals were stored in wav files with a sampling frequency of 156 or $312 \mathrm{kHz}$. The system was mounted on a Carlson river board, drifting during the measurements. The hydrophone was located under the river board at a constant depth, between 0.3 and $0.8 \mathrm{~m}$ from the water surface depending on the water depth of each river. Lagrangian measurements were preferred to fix-position measurements to optimize the signal to noise ratio. Six to twelve drifts were done along each cross-section, at equally spaced locations. Each cross-sectional location was repeated at least 3 times. Drift duration varied from 10 to 60 seconds according to field constrains. The median Power Spectral Density (PSD) of each drift has been computed using windows of approximately 20 milliseconds with a recovery rate of $50 \%$.
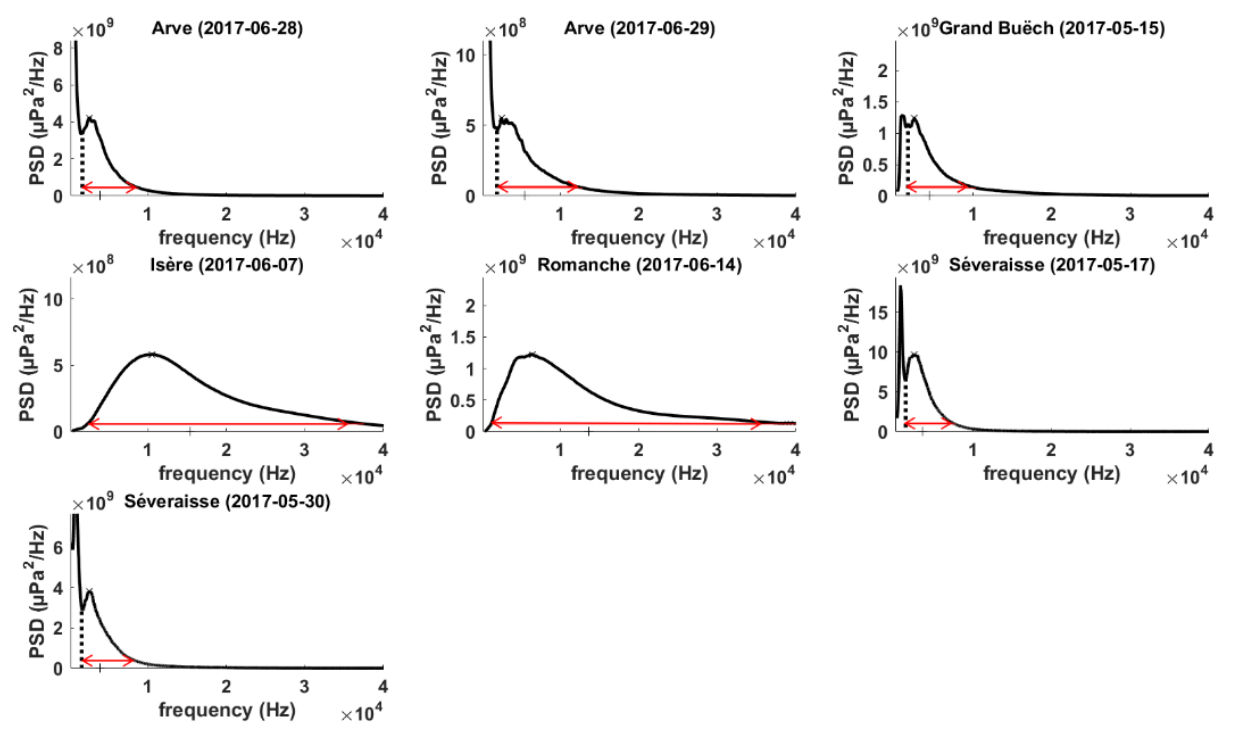

Fig. 2. Cross-sectional averaged Power Spectral Densities (PSD) monitored for each field experiment. Red arrows indicate the part of SGN signals that are dominated by bedload transport noises. The dot lines (black) separate the frequency region dominated by water flowing noises (lower frequencies) from bedload noises (higher frequency range).

Bedload SGN can be heard in the higher frequency domain. Water flowing noise can also be recorded, it creates a bi-modal distribution of the PSD (Fig. 2). To avoid the contribution of water flowing noise, an acoustic power was computed by integrating the $P S D$ between $2 \mathrm{kHz}$ and $75 \mathrm{kHz}$. As for bedload-flux, acoustic power (for each crosssectional location) has been averaged:

$$
P_{S G N}(X)=\frac{\sum_{i}^{N} \int_{2}^{80} P S D_{i}(X \pm \Delta X, f) d f}{N}
$$

Where $N$ is the number of drifts made at the locations $\mathrm{X} \pm \Delta X, X(\mathrm{~m})$ is the cross-sectional location of the SGN measurement, considered to be invariant during the drift (straight reaches) and $\Delta X(\mathrm{~m})$ is a window of $1 \mathrm{~m}$ used to average the data in the spatial domain. 
Missing value of the profile were linearly interpolated. Finally, the average-specific acoustic power is obtained by integrating the profile:

$$
\overline{P_{S G N}}=\frac{\int P_{S G N}(X) d X}{W_{\text {river }}}
$$

The estimated standard deviation of the acoustic power is computed by summing the squared standard deviation obtained at each location:

$$
\overline{\sigma_{P}}=\frac{\sqrt{\int \sigma_{P}(X)^{2} d X}}{W_{\text {river }}}
$$

\subsection{Active acoustic monitoring}

Acoustic Doppler current profiler (aDcp) was used to measure discharge during the experiments, and also to estimate a bedload velocity using the bottom-track (BT), i.e. the relative velocity between the instrument and the bottom. The process has two parts; first identify the position of the bed from the acoustic echo, then calculating the relative velocity between the bed and the aDcp. If the bed is moving (bedload), the BT is interpreted as an upstream displacement of the aDcp [12].

Active acoustic measurements were done with a SONTEK M9 operating at a frequency of $1 \mathrm{MHz}$ and equipped with a Differential GPS. A calibration procedure of the compass has been performed before the measurements. For each cross-sectional location, a 5 minutes deployment of the aDcp was achieved at a fixed position. The apparent bedload velocity is computed as:

$$
v_{a D c p}(X)=\frac{L(X)}{d(X)}
$$

Where $L(\mathrm{~m})$ is the upstream ward distance virtually travelled by the aDcp (BT information) and $d(\mathrm{~s})$ is the duration of the measurement.

\section{Results}

Spatial variations of the measurements are plotted in the Figure 3. It represents the variation of specific bedload flux $(\mathrm{g} / \mathrm{m} / \mathrm{s})$, acoustic power $\left(\mu \mathrm{Pa}^{2}\right)$ and apparent bedload velocity $(\mathrm{m} / \mathrm{s})$ according to the integral of these parameters along the cross-section. In most of the field sites, SGN profiles are consistent with sampling profiles. Larger differences are observed for the Grand-Buëch and Isère rivers, where sampled bedload fluxes exhibit a narrower active channel. These incoherencies could be attributed to the partial occurrence of bedload transport along a cross-section. Bedload sampling measurements are local whereas hydrophone measurements are integrative of a larger, but unknown, river-bed area. Near the banks, where bedload transport is quasi-null, the hydrophone records an acoustic activity which is not necessarily generated at the location of the measurement: bedload SGN is propagated from the channel of bedload transport to the hydrophone located near the banks. aDcp profile of apparent bedload velocities are also plotted for the Isère and Romanche rivers. For the Romanche river, the aDcp profile looks like the profile obtained with sampling measurements. For the Isère river, a shift of the maximum is observed. The Isère river is the only site where a cross-sectional grain-size sorting has been observed. Bedload grain-sizes have been observed to shift from sand to gravel from left to right bank, as it has been measured in 2016 [15]. The report of [16] indicated that the measurement of apparent bedload velocity was more successful with sand bed than with gravel-bed 
experiments. In the Isère river, this could explain the shift of the aDcp profile toward the left bank, where finer materials are transported.

The average response of the hydrophone is compared to the average specific bedload flux in Fig. 4. For 4 different rivers, a linear relationship between SGN acoustic power and bedload flux has been plotted. The measurements made in the Arve river are outside the main tendency: less acoustic energy has been measured in comparison to the other sites (in proportion to the sampled mass). Bedload grain-sizes sampled in the Arve river are mostly sand (table 1) and are similar to those measured in the Romanche river. However, the measurement made in the Romanche river is in the global tendency. Looking at the spectra obtained for the Arve and Romanche rivers (Fig. 2), it can be found that their spectral characteristics are different. In the high frequency range, higher acoustic power has been monitored in the Romanche river than in the Arve river. Spectrum shape of bedload SGN should be mostly determined by grain size distributions [8]. However, spectrum shape are also affected by propagation effects [10]. As bedload granulometries have been found to be similar in both rivers, we think that propagation properties are the main factor explaining that the Arve river is out of the tendency. A larger attenuation of the acoustic waves in the Arve river would lead to lower acoustic power measured. By the way, acoustic propagation measurements (similar to those made in [17]) indicated that the attenuation of acoustic waves was stronger in the Arve River than in the Romanche river. The experiment has been done with an underwater soundspeaker operating in the $0.2-20 \mathrm{kHz}$.
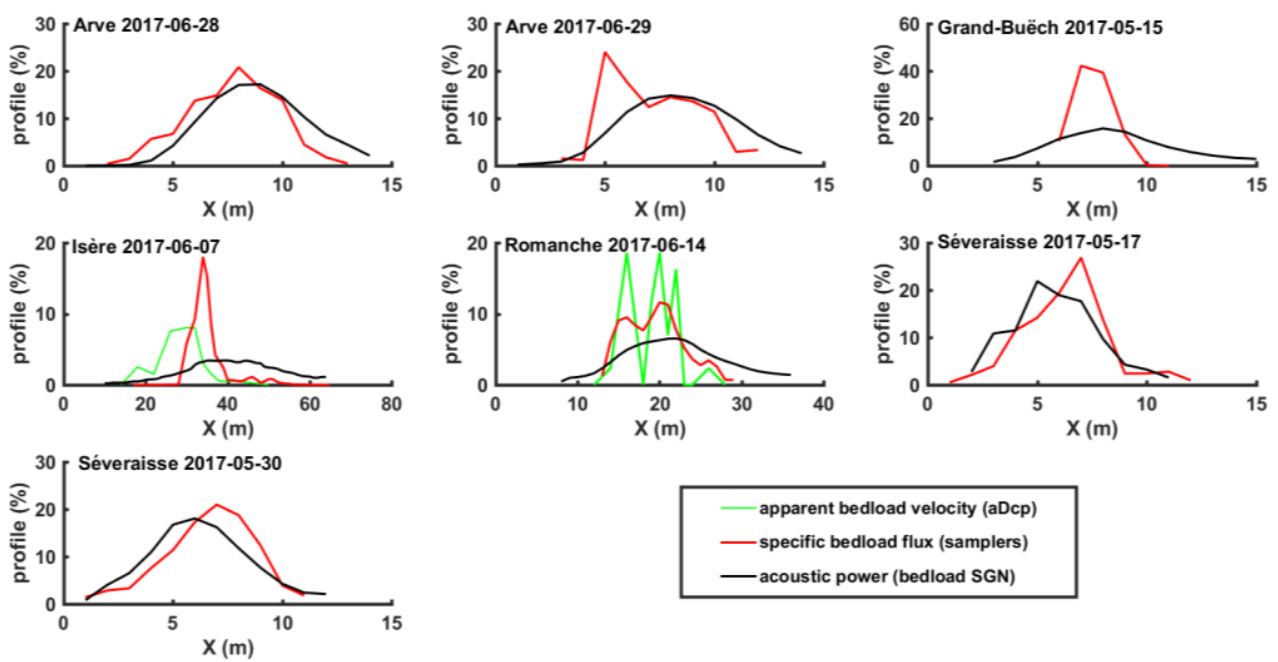

Fig. 3. Cross-sectional profiles measured with aDcp, bedload samplers and bedload SGN measurements for each river. Each profile was obtained by dividing the parameters monitored at point $\mathrm{X}$ by the integral of the parameter along the cross-section. 


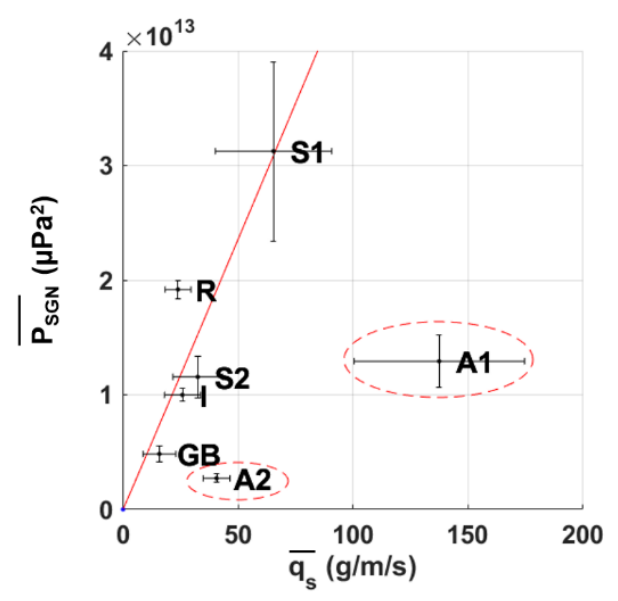

Fig. 4. Averaged acoustic power $P_{S G N}\left(\mu \mathrm{Pa}^{2}\right)$ in function of averaged specific flux $q_{s}(\mathrm{~g} / \mathrm{m} / \mathrm{s})$. Plotted uncertainties are plus/minus an estimated value of the standard deviation of the measurements (eq. 3 and 6). Linear regression (red line) has been fitted by excluding the points A1 and A2.

\section{Conclusion}

A field campaign has been achieved in 5 different rivers. Passive and active acoustic measurements were compared to direct sampling measurements of bedload transport. SGN measurements showed a linear relationship between the averaged acoustic power and the bedload specific flux for 4 over 5 rivers. The Arve river data highlighted a different behavior. Based on the observation of SGN spectra, propagation effects are suspected to be the source of inconsistency in the laws linking SGN power to bedload flux. Additionally, the profiles obtained with SGN measurements differs from sampling profile as the sound of bedload impacts are propagated from location of bedload transport to location of zerotransport. Finally, we conclude that additional processing of SGN data are required to deconvolute the acoustic signals from propagation effects. Without this deconvolution, SGN measurements are too much dependent on propagation effects that are not related to bedload fluxes. Concerning the measurement of apparent bedload velocity with aDcp, it has been observed that the cross-sectional profile could be affected by grain-size variations, resulting in a slight bias in bedload transport locations.

A lack of accuracy between surrogate methods and direct bedload samplings has been observed in this study. However, we did not discuss the accuracy of bedload samplings. Particularly, the time needed to sample the entire cross-section at a constant flow is one of the limitation of the method. Acoustic measurements can be performed over shorter time periods ( 30 minutes to 1 hour in this study) which would considerably improve bedload samplings. Even if some bias is observed in the profile, areas of maximum transport can be rapidly identified and help to choose the locations where the effort of bedload sampling should be done.

The authors acknowledge Guy Cellier, Ludovic Michel and all the students that were helpful in the collection of these data. 


\section{References}

1. J.R. Gray, J.B. Laronne, J.D.G Marr, Bedload-Surrogate Monitoring Technologies Scientific Investigations Report 2010 - 5091. : 37 (2010)

2. M.D. Marineau, A. Gendaszek, C. Magirl, Proceedings of the Hydraulic Measurements and Experimental Methods Conference : 1-6 (2012)

3. M.D. Marineau, S.A. Wright, D. Gaeuman, In Proc. of River Flow conference : 1519$1526(2016)$

4. T. Geay, P. Belleudy, C. Gervaise, H. Habersack, J. Aigner, A. Kreisler, H. Seitz, J.B. Laronne, Journal of Geophysical Research: Earth Surface 21: 2010 (2017)

5. K. Bedeus, L. Ivicsics, General Assembly, Commission on Hydrometry, International Association of Hydrological Sciences, Berkeley, CA, USA : 19-31 (1963)

6. M.S. Lorang, D. Tonolla, Fundamental and Applied Limnology 184: 231-246 (2014)

7. C.K. Jonys, Scientific Series 64 (1976).

8. P.D. Thorne, Earth Surface Dynamics 2: 531-543 (2014)

9. J.R. Rigby, D.G. Wren, R.A. Kuhnle, Journal of Hydraulic Engineering 142: 2516003 (2016)

10. T. Geay T, P. Belleudy, J.B. Laronne, B. Camenen, C. Gervaise, Earth Surface Processes and Landforms 42: 2447-2456.DOI: 10.1002/esp.4208 (2017)

11. D.G. Wren, B.T. Goodwiller, J.R. Rigby, W.O. Carpenter, R.A. Kuhnle, J.P. Chambers, Proceedings of the 3rd Joint Federal Interagency Conference (10th Federal Interagency Sedimentation Conference and 5th Federal Interagency Hydrologic Modeling Conference), April 19 - 23, 2015, Reno, Nevada. : 408-413 (2015)

12. C.D. Rennie, R.G. Millar, M. Church, Journal of Hydraulic Engineering-ASCE 128: 473-483 (2002)

13. C.D. Rennie, P.C. Villard, Journal of Geophysical Research 109: F03003 (2004)

14. D. Gaeuman, R.B. Jacobson, Journal of Geophysical Research 111: F02005 (2006)

15. T.I. Petrut, T. Geay, C. Gervaise, P. Belleudy, S. Zanker, Hydrology and Earth System Sciences Discussions: 1-34 (2017)

16. R. Ramooz, C.D. Rennie, Geological Survey Scientific Investigations Report 20105091 : 367-386 (2010)

17. J.R. Rigby, D. Wren D, N. Murray, River Flow Conference : 1566-1570 (2016) 